\title{
Exploring Dynamics of Facebook Health Support Groups: a Leadership Perspective
}

\author{
Rosta Farzan \\ University of Pittsburgh \\ rfarzan@pitt.edu
}

\author{
Charles Jonassaint \\ University of Pittsburgh \\ jonassaintcr@upmc.edu
}

\begin{abstract}
Online health support groups are among the most popular Internet groups, being employed daily to share and seek health-related information, support, and advice. The leaders of these groups often employ various strategies to encourage and regulate participation. In this work, using a mixed methods data collection and research methodology, we follow a health support group leadership framework to examine how the organic peer-leadership strategies grows in two distinct Facebook groups, both dedicated to patients with Sickle Cell Disease. Our results highlight how these organic leadership strategies follow the standard leadership frameworks in more traditional context. Our results also shows that different leadership strategies lead to different group dynamics in terms of level of interaction and content of the discussions.
\end{abstract}

\section{Introduction}

The Internet has been increasingly used to share and seek health-related information, support, and advice [1]. Many individuals, especially those in chronic conditions and those suffering from serious diseases such as cancer turn to various online sources such as online discussion forums for social support. The support individuals can receive through these online platforms is highly dependent on the amount and pattern of interaction happening on these groups. While there exists a large number of online health related discussion forums, many groups experience lack of activities and a high drop-out rate. For example, $60 \%$ of members joining the breastcancer.org discussion forums never return after their first post [2]. To encourage engagement and active participation, many of the online communities attempt to regulate participation through different leadership and moderation strategies.
Research on offline health support groups has documented a strong relationship between leadership and therapist strategies and helpful group experiences that lead to positive outcomes such as improved selfesteem and more positive self-concept [3]. It has been shown that leadership structure, especially in terms of meaning attribution; i.e. assisting members to understand group better, has been associated with positive group outcomes. These positive outcomes have often been achieved through mediating the group climate in terms of increasing engagement and interaction among group members and decreasing conflict [4]. Leadership practices resulting in creating safe environment for group members have been associated with an increase in group members' engagement. Matzat and Rooks [5] studied moderation strategies across dimensions of direct vs. indirect and positive rewarding vs. negative punishment. Their results suggest that indirect forms of moderation that rely on intrinsic motivations of members are most effective in terms of encouraging active participation. Overall, leadership and facilitation behavior have been found instrumental to increase social support in health support group by promoting both task-oriented and socio-emotional processes [6].

Despite the consistent identification of the importance of the leadership strategies in offline and face-to-face health support groups, there has been little attention to the studies of online support groups. While online groups share a great deal of similarity with physical face-to-face group, online interactions demonstrate uniqueness as well, such as distinct level of emotional expression, conflict resolution, use of discourse approaches, and intensity of self-disclosure and information sharing [7]. There has been less attention on how leadership, facilitation, and moderation strategies influence interaction in online groups. Beyond encouraging active participation, the leadership strategies are particularly important for online health communities since the effectiveness of these groups can directly influence health and well- 
being of their users and misinformation can lead to serious harm to patients using these platforms. Within the online health support groups, the leaders often arise from a dedicated member of the patient community who most likely shares similar health challenges and recognizes the deep need within the community and themselves, for increased social support [8]. These self-selected leaders are typically organizing the group without formal training on group leadership and they employ various strategies organically and from their personal experiences. It is critical to understand how the leadership strategies affect the group dynamics and how they influence interaction patterns in the online health support groups. A better understanding of such phenomena inform scholars about group processes and provides valuable feedback to these self-motivated member-leaders.

In this paper, we have attempted to further the research in this area by studying the leadership and management strategies of two distinct Facebook groups for patients with Sickle Cell disease in terms of how their peer-leadership strategies influence the interaction patterns and the content of discussions in the groups. We should emphasize that our paper is not an experimental research and it is an exploratory study of two groups from the leadership perspective. Nevertheless, our paper contributes to understanding of online groups, and particularly health support groups by (1) studying two Facebook health support groups as examples of one of the most health support group platforms (2) studying a framework from offline groups in the online context; (3) studying the groups from their leaders' perspective; and (4) providing a well-refined coding schema of discussion topics in online health support groups.

The rest of the paper is structured to provide (1) details on each of the Facebook groups, (2) explanation of our mixed methodology to collect quantitative and qualitative data, (3) presentation of the leadership framework in offline health support groups and how it applies to the groups we studied, and (4) the results of the analyses of group dynamics and interactions in terms of the semantics and topic of the content discussed in each group, and interactions among group members around the content.

\section{Online health support group}

We identified two Facebook groups dedicated to providing supports for patients with Sickle Cell disease, each employing distinct leadership and management strategies. These two groups are the most popular online health groups supporting Sickle Cell patients and their care givers. The popularity among the Sickle Cell patients motivated our studies of these groups. Sickle-Cell warriors [9] was started in May 2005 and is a moderated public Facebook page whose creator and primary owner is both a registered nurse and a patient living with sickle cell disease. The administrators of the Sickle Cell Warriors support group manage the content and tempers the posts on the page by selecting and highlighting on the page those posts they believe will be the most relevant to other members; however, all of the posts on the page are publicly visible.

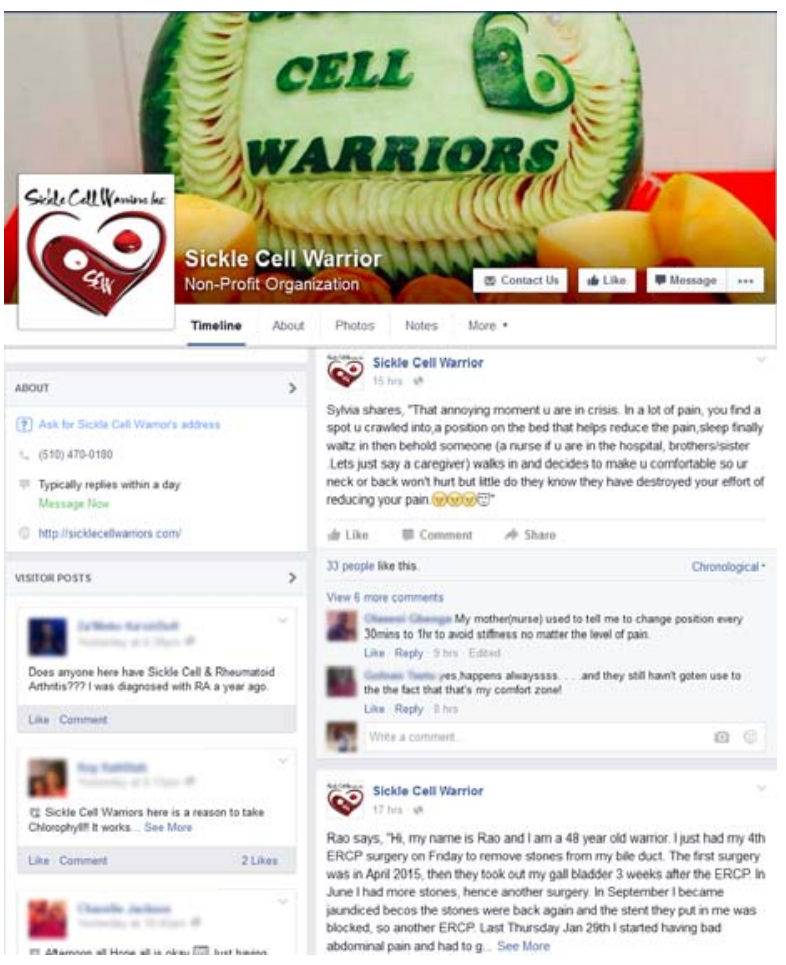

Figure 1 - Sickle Cell Warriors page on Facebook

As shown in Figure 1, the page is public and all the posts are shown to the visitors. However, the posts most visible on the right side of the page are all moderated by the administrators of the page. Visitors are able to submit any posts, the approved posts appear on the left side of the page. Further, the leader of Sickle Cell Warriors page reviews all the messages submitted by the members and decides to highlight the ones she finds particularly important and relevant, prefixed with the name of the original author, such as "Sylvia shares..." or "Rao says...". 


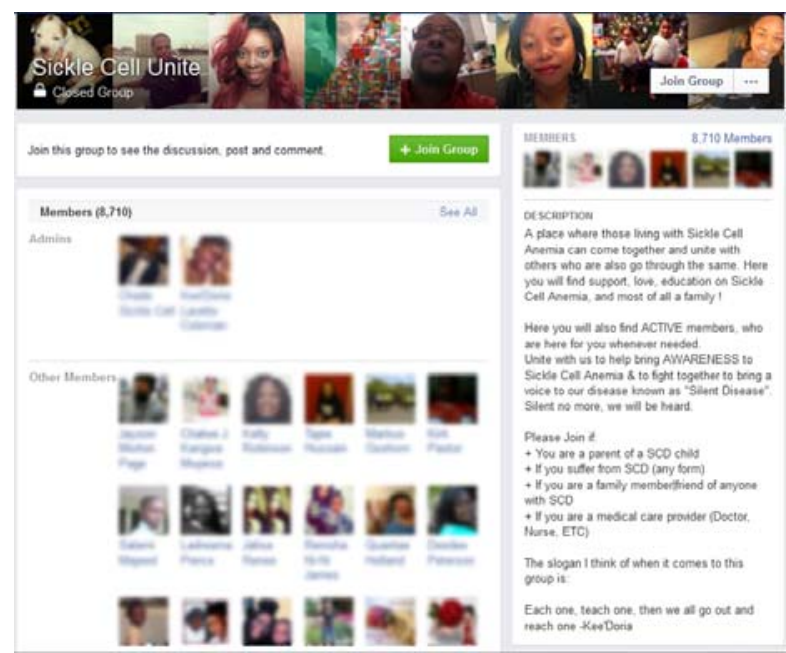

Figure 2 - Sickle Cell Unite group on Facebook

Sickle Cell Unite [10] is another Facebook support group dedicated to sickle cell disease, started in 2009 by a patient living with sickle cell. In contrast to Sickle Cell Warriors, Sickle Cell Unite is a closed private Facebook group and each membership request needs to be approved by the group administrators. The messages and content, as shown in Figure 2, are only visible to members of the group, and only group members can post or comment. Once someone becomes part of the group, however, there is very little moderation of messages posted to the group. The group is particularly encouraged to share very personal and often controversial topics. An important distinction between Sickle Cell Warriors and Sickle Cell Unite is that, the Warriors page is a Facebook page as opposed to a Facebook group and the most visible posts on the page are controlled by the owner of the page and the direct posts from the members only appear on the left side of the page in a small box. Facebook pages are designed to represent entities publicly visible to everyone on the Internet by default while Facebook groups are for small-group communication [11]. Visitor of a Facebook page can express their interest on the page by becoming a fan of the page. Facebook group can have different privacy controls that is decided by the creator of the group. The can be "publicly available to anyone", "require administrator approval to join", or "private and by invitation only". In any case, individuals interested in the group will join the group as members of the group. There are fundamental structural differences among Facebook groups and Facebook pages that can influence the dynamics of interactions happened in each of those spaces. Therefore, the leader decision to initiate their group in each of those spaces can lead into further impact on the group dynamics that we hope to highlight in this work.

\section{Mixed methods data collection and analysis}

Given the complexity of group dynamics, we used a mixed methods approach to determine the impact of different leadership and management strategies on group dynamics. This approach involved three different data and analytical strategies. First, we conducted qualitative interviews with the primary leaders of each sickle cell support group to determine their leadership strategies. Second, we extracted the content of the messages through Facebook API and performed regression analyses to examine group differences in member responses to posted messages (e.g. number of likes and comments) in connection to those leadership strategies. Finally, we randomly sampled and manually annotated a set of messages to determine the types of communications and the concepts and topics being discussed within each group and study whether the impact of leadership strategies are reflected in the content of messages.

\subsection{Interviews with group leaders}

We conducted a semi-structured interview with the leader of both groups to learn about the history of the group and their leadership strategies. The interviews lasted 35 to 50 minutes. Questions included topics on "why and how did you get motivated to start the group?", "at what level are you engaged with the group?", "how has the group grown into a well-known community among Sickle Cell patients?", "how do you encourage participation of your members?", "over time what decisions have you made to ensure the survival of the online community?", and "what do you see as the challenges of the community? the future of the online community? and how it can contribute to addressing some of the challenges faced by Sickle Cell patients?". The interviews were audio-recorded with the permission of the participants and were transcribed using TranscribeMe (http://transcribeme.com/) services. We analyzed the transcription of the interviews to highlight their responses to our major questions regarding their leadership strategies and survival of their online community.

Based on Lieberman and Golant [3] model of leadership, we coded each leader's expressed strategies employed using four categories: (1) evoke-stimulate emotion, (2) support-caring function, (3) meaning attribution, and (4) executive-management function. 
The Evoke-stimulate emotion category represents strategies to elicit emotional responses. The supportcaring function category includes strategies to offer support, friendship, and affection. The meaning attribution category refers to strategies aimed at providing a cognitive structure to the group with the goal of reducing uncertainty and anxiety among members. The executive-management function category denotes strategies to manage the group as a social system with rules, guidelines and suggestion.

\subsection{Extracting message data through Facebook API}

To gain insight into groups' interaction patterns, we used the Facebook API to extract data of all posts made in each group and the associated interactions for a period of 13 months, from February 2014 until February 2015. The data are collected under approval of owners of Sickle Cell Warriors and Sickle Cell Unite Facebook support group and the study was approved by the University of Pittsburgh Institutional Review Board. In case of the private group, with the approval of the group leader and the IRB, one of the researcher joined the group and his identification with group was utilized within the Facebook API to collect data. For each post, we collected the content of the message, the ID of the user posting the message, and the time the message was posted. In terms of interaction around each message, we collected information about "likes" and comments each message had received. Liking information included the id of the user liking the post. The comments' information included the id of the user posting the comment, the message of the comment, the time the comment was posted, and how many "likes" the comment had received. Descriptive statistics of our data is presented in Table 1.

\section{Table 1 - Descriptive statistics of Facebook groups}

\begin{tabular}{|l|l|l|}
\hline & Warriors & Unite \\
\hline Total \# of members & 16,107 & 8.403 \\
\hline Total \# of messages & 1,252 & 13,107 \\
\hline $\begin{array}{l}\text { Total \# of unique } \\
\text { contributors }\end{array}$ & 376 & 1,877 \\
\hline
\end{tabular}

\subsection{Interaction around messages}

We conducted regression analyses to compare interactions happening around posts in each of the groups. To measure the interaction, we considered four different dependent variables: number of likes given to a post and number of comments added to a post as measures of amount of interaction since likes and comments are the common approaches among Facebook users to interact with each other. Furthermore, we used time to the first comment and last comment in minutes as measures of dynamism and enthusiasm of the interaction since they represent how quickly a message draws the attention of the community and how long after the message is posted the community is still paying attention to that message. Each model considered the group, and whether the message was posted by the leader or members as the independent variables. To test group differences on interaction features, we used Stata GEE model with userid to define the panel structure to account for multiple messages per user. Contingent on the distribution of the dependent measure, we modeled the data with Gaussian distribution for time variables and Negative Binomial for count data of likes and comments. To achieve normal distribution for the time variables, we log transformed the variables. Also, before log transformation, we normalized the time to last comment by the number of comments since there is a high chance that higher number of comments could be associated with longer time to last comments.

\subsection{Manual annotation of topics of Facebook posts}

To gain more understanding of the dynamics of the groups, we analyzed a randomly selected subset of messages to determine the types of posts/comments and the concepts or topics being discussed on each of the group pages. Using the constant comparative method [12], we developed a coding dictionary used to label concepts, topics or process features of the Facebook posts. To develop the dictionary, we randomly selected 200 posts to be analyzed by three of the investigators. Using an inductive approach with no apriori assumptions, posts were compared using a stepwise process. First, data from each post were categorized during an open coding process. Next, posts were compared across posts to yield integration or refinement of categories, including grouping related categories. Some categories were eliminated due to low frequency. By using the core or main categories that emerged, we established a category coding scheme. This resulted in 15 categories that described the type of communication and content of the post. The coding schema with an example for each category is displayed in Table 2.

These categories were then detailed in a coding dictionary that included a description, key words, and examples for each category. Two new annotators were trained on how to use the coding dictionary and used it 
to code a new set of 128 randomly selected posts. The original 200 messages used for training and constructing the code book were discarded and not used in our final analysis. To ensure applicability of the code book, for the final analysis, we employed a new set of messages. The random selection process was done by generating a random set of numbers corresponding to post IDs. The selection process ensured representation of posts from both groups. However, the annotators were uninformed about the source of each post. Annotators were asked to code each post with a minimum of one and maximum of three categories. Kappa statistics were used to determine inter-rater agreement for the categorization of posts by the three independent annotators. To account for multiple coding categories per post, each pair of post-category were represented as a single record in calculation of Kappa agreement. We believe that our careful development of dictionary and training of the annotators resulted in high agreement among them. We achieved $75 \%$ agreement between the two annotators with Kappa $=0.73$.

Table 2 - Coding schema for annotation of topics of the Facebook messages

\begin{tabular}{|c|c|}
\hline Category & Example \\
\hline advertisement & $\begin{array}{l}\text { hey everyone } i \text { will be making and selling theses shirts. if you would like one let me know! } \\
\text { the prices are white is } \backslash \$ 20 \text { and colors are } \ \$ 23 \text { plus sizes are } \backslash \$ 3 \text { extra }\end{array}$ \\
\hline care experience & $\begin{array}{l}\text { last night while in the ER I had an ER doctor tell me that Sickle Cell Hemoglobin SC Disease } \\
\text { is the same as Sickle Cell Trait. I responded by saying no it's not and he walked off. This is } \\
\text { the first time I've ever heard a doctor say that. }\end{array}$ \\
\hline encouragement & Look y'all lol. KEEP GOING \\
\hline family planning & What's the odds of one parent having the trait and child coming out with SS \\
\hline finances & $\begin{array}{l}\text { Does your insurance company make you pay hi co-payments? Please help i need to go to the } \\
\text { hospital but my insurance is telling me i have to wait a } 60 \text { day period? }\end{array}$ \\
\hline God/prayer & $\begin{array}{l}\text { I haven't been feeling well since last night but im going to still keep my head up and smile } \\
\text { cause i know that God has my back }\end{array}$ \\
\hline $\begin{array}{l}\text { medication/treatm } \\
\text { ents }\end{array}$ & What experience good or bad have you had or seen with hydroxyurea? \\
\hline pain experience & $\begin{array}{l}\text { my } 17 \text { y.o. daughter has been in pain unrelieved by narcotics since November, what else can } \\
\text { she try? }\end{array}$ \\
\hline relationships & $\begin{array}{l}\text { How many of my warriors feel alone,like the black sheep of family, have no support,like } \mathrm{u} n \text { it } \\
\text { all by urself.Basically } \mathrm{u} \text { have no friends,no one calls } \mathrm{u} \text { or come by } \mathrm{n} \text { even family } \mathrm{n} \text { friends } \\
\text { etc,treat } \mathrm{u} \text { like } \mathrm{u} \text { just addicted to the meds.No boyfriend or girlfriend or if } \mathrm{u} \text { do,relationships } \\
\text { never last long. Who going thru like this? }\end{array}$ \\
\hline seeking support & I need all of my Sickle Cell Warriors to say a prayer my son. \\
\hline $\begin{array}{l}\text { seeking } \\
\text { information }\end{array}$ & $\begin{array}{l}\text { GM Family I just wanna know do any of } u \text { have trouble with ur appetite and if so is their } \\
\text { anything ur Dr. gives } u \text { to help? Needing Help From You Guys ;) }\end{array}$ \\
\hline $\begin{array}{l}\text { Seeking shared } \\
\text { experience }\end{array}$ & Anybody plagued with Musculoskeletal Pain? \\
\hline self-expression & $\begin{array}{l}\text { Enjoyed the comedy show last night in spite of some pain laughter is definitely good } \\
\text { medicine!!! }\end{array}$ \\
\hline $\begin{array}{l}\text { sharing } \\
\text { information }\end{array}$ & $\begin{array}{l}\text { I just heard of a } 504 \text { Plan for children with disabilities like } \backslash \# \text { sicklecell This is an educational } \\
\text { opportunity for parents. }\end{array}$ \\
\hline $\begin{array}{l}\text { stigma/ } \\
\text { discrimination }\end{array}$ & $\begin{array}{l}\text { Doctors have no respect for people with sickle cell. They think we lie about our pain that we } \\
\text { have.? }\end{array}$ \\
\hline
\end{tabular}




\section{Results}

\subsection{Leadership model in the Unite and Warriors Sickle Cell groups}

Using qualitative data from semi-structured interviews we were able to identify leadership strategies used in each Facebook online support group.

Evoke-stimulate emotions: It represents the degree in which the leader uses tactics and strategies to elicit emotional responses, often through "uses of self" and indication of personal experiences. High intensity emotional stimulation often includes personal revelation, challenging, and confronting. Lower level of stimulating behavior includes invitation, elicitation, and questions. This use of self and strong level of evoking emptions were explicitly highlighted in our interview with the Sickle Cell Unite group leader, as presented below, who encourages members' participation through her own posting behavior:

I would go and -- when sickle-cell awareness month started, I figured I would start to share more of me to give them, to make them want to be into something like this. I think maybe two years ago when I did sickle-cell awareness month, I shared three facts every day, and then I shared three or four personal facts because people were scared to talk about certain things because they didn't want to be judged.

When the leader of the group went ahead - I'm sharing personal things, really very raw personal things - everyone else started speaking up...

On the other hand, the leader of Sickle Cell Warriors uses lower level strategies of evoking emotions through elicitation and invitation. She highlighted that she tries to invoke her members' engagement by eliciting themes she finds most resonating with them more than use of self and personal stories:

I would like to know which themes are the most that people resonate with because then I can write posts that really stick with that and buck up other categories that don't.

Or by invitation such as "the question of the day":

We would take one question out of all questions that we got that day
Support-caring functions: It denote strategies designed to offer support, friendship, and affection. Both groups are very intense in terms of providing high level of support for their members. Having personally experienced the complications of Sickle Cell, the leaders of both groups have been working hard on offering a platform to give a sense of "unity and positiveness among the patients and caregivers", "increase awareness", and "support a sense of community":

I came up with Sickle Cell Unite, because as I was studying more and more about sickle-cell, I saw that there wasn't a lot of unity within the people, like there was for other diseases...They were all positive together. I wanted that for sickle cell. I wanted there to be some kind of unity and I wanted it to be not only between the people, but with us and the doctors, so we can get more help. So I made the group.

Further, as highlighted in the quote below, she told us about how she could not give up on managing the group when it felt overwhelming to her because of the reaction of the community and her commitment to provide support and care to them:

People were like, "please don't delete it. I need this to live. You're my inspiration. If you can get through what you go through, I know I can go through the little stuff that I go through. I've never had something like this before ever. This has become like a family for me." I didn't want to delete it because it had become like this big, great savior for some people. They needed it....I also felt like if I deleted it, I would be giving up on my own people. I just couldn't live with that. It would bother me to know that I gave up.

Similarly, the leader of the Warriors group highlighted how she had been spending a significant amount of time on the group to provide support to the members, especially at the beginning of starting the group:

I used to spend a lot more when I first started. I would say I was probably spending about 20 hours a week...I used to say Sickle Cell Warriors is my baby.

Meaning attribution: It refers to strategies employed to provide a cognitive structure to the group members with the goal of reducing uncertainty and members' anxiety. Example of such strategies include labeling experiences to provide perspective to 
members or providing exercises. Both groups provide a relatively high structural support by regularly posting in the group to provide examples of appropriate content and by responding to posts of others. They also try to encourage participation through structured exercises such as "three facts every day" in the Unite group or "challenge of the month" in the Warriors group as highlighted below:

We used to do this challenges, and we would all decide-- like I would post, "Okay, now we're going to brainstorm for our challenge." And we decide what the challenge was going to be for the month. And then we would all encourage ourselves to do it. It would always end up being something healthy like sleep eight hours at night or drink ten cups of water or whatever, and we would all post through the day, "Hey, I've done mine. I did the challenge," and people were supper giged and supper excited to participate in the challenge. So we used to do things like that, and that really did yield a lot of support from the community.

Executive-management: It refers to strategies employed to manage the group as a social system in the form of guidelines, rules, and suggestions. Leaders of each group has made specific design decisions in terms of executive management of their group. The first and very important decision is in terms of the private vs. public nature of the group. The leader of Sickle Cell Warriors specifically believes in public group and information being publicly available to all. This was specifically highlighted as she responded to our question of whether she would still keep the group public if she converted the Facebook page into a Facebook group which has the option of being private:

I would keep it as a public group...because I really felt, back in 2005, I was in hospital and I was looking for someone out there who was going through the same thing I was going through, and I really couldn't find anything back then. So I always just believe that just for the sake of other people coming behind us, so that they don't feel alone, we need to share our experiences, good bad, indifferent, whatever.

As opposed to that, the leader of Sickle Cell Unite strongly felt that the group should be private and being able to control privacy was a big factor motivating her to start the Sickle Cell Unite group:

As I started to go in these [sickle cell] groups that I found, .... I realized that they weren't private. Whatever we said went to our [public] news feed and our friends could see...but some topics you don't want people to see or don't want them to know about you at the time, because people hide a lot of stuff with sicklecell...So I said, Okay. Fine, I'll make a group, I'll make it private and I'll tell you guys what it is and I'll invite you.

On the other hand, Sickle Cell Warriors has a very intense guidelines and rules strategy. The leader has defined very explicit rules about "Dos and Don'ts" and she has dedicated a page to outlining all of those rules ${ }^{1}$ and she closely follows these rules. She specifically raised that issue in the interview:

I think we are the only page that actually has rules...it was like in 2011 maybe when we came out with the community guidelines, and it was just as a response to what was happening on the page. Because we had such an influx of people, and people were starting to fight, people were starting to argue, and it was just like, "Okay, guys. This is what I expect from you, and this is what you can expect from me. These are the rules, and we're going to enforce them consistently" I didn't like what it was becoming. So the rules naturally grew from that. So each one is actually because something happened that caused us to put it in the rules.

Members who do not observe the rules receive a warning with a link to the rules page and after receiving two warnings they will be banned from the page. The Sickle Cell Unite support group, in contrast, does not provide any explicit indications of rules and has much more relaxed policies in terms of moderation of the posts. While the administrators moderate the group as issues arise, they support more freedom in terms of what is allowed because the group is private and the messages will be only available to members.

We really don't have a set of rules - rules and regulations. It's free and open. Don't disrespect anybody, you won't get disrespected.

$\cdots$

\footnotetext{
${ }^{1}$ https://www.facebook.com/notes/sickle-cellwarrior/community-guidelines/10152727066717417
} 
As far as when it comes to topics, as long as you don't make a post about a certain person, and you put their name and tag them and then you start attacking them, we don't allow any of that. We don't allow the attacking. If we're talking about something-- a healthy debate is nice.

Table 3 - Leadership strategies in Unite and Warriors group

\begin{tabular}{|l|l|l|}
\hline & Unite & Warriors \\
\hline $\begin{array}{l}\text { Stimulating } \\
\text { emotions }\end{array}$ & $\begin{array}{l}\text { Intense through } \\
\text { use of self }\end{array}$ & $\begin{array}{l}\text { Light through } \\
\text { elicitation }\end{array}$ \\
\hline $\begin{array}{l}\text { Support } \\
\text { function }\end{array}$ & $\begin{array}{l}\text { Similar high support as a result of } \\
\text { personal connection to Sickle Cell }\end{array}$ \\
\hline $\begin{array}{l}\text { Meaning } \\
\text { attribution }\end{array}$ & $\begin{array}{l}\text { Similar through personal participation } \\
\text { and providing exercises }\end{array}$ \\
\hline $\begin{array}{l}\text { Executive } \\
\text { function }\end{array}$ & $\begin{array}{l}\text { Private with open } \\
\text { rules }\end{array}$ & $\begin{array}{l}\text { Public with } \\
\text { restricted rules }\end{array}$ \\
\hline
\end{tabular}

\subsection{Group interaction around messages}

Interviews with the leaders highlighted differences and similarities in strategies used by each group in maintaining and sustaining their group. Interactions among the group members is an important factor in sustainability of any online groups [13], and especially health support groups [4]. On Facebook groups, members can interact with each other by posting messages, liking messages posted by others, or commenting on messages of others. We were interested to study how these interactions patterns existed in each of the Sickle Cell groups, given the differences in the leadership strategies and design decisions made by each leader.
In summary, while the group leaders share some aspects of leadership strategies, such as caring functions and cognitive support, they make distinct decisions in the way they manage the group. We have summarized the presence of each dimension of the leadership framework in each group in Table 3.

Regression analyses showing group differences in number of likes and comments per post and time to first comment and last comment are shown in Table 4. The results show that higher amount of interaction happens around the messages on the Sickle Cell Unite group. Sickle Cell Unite messages on average receive 3.73 times more likes and 3.18 times more comments. Moreover, the messages on the Unite group attract attention faster; i.e. on average the time between the post and the first comment is shorter (Estimated mean: Unite $=15 \mathrm{~min}$ vs. Warriors $=5$ hours); however, the discussion through the comments on Warriors continues for a longer period of time; i.e. on average the time between the post and the last comment is longer on Warriors (Estimated mean: Unite $=1$ hour vs. Warriors $=10$ hours). The results suggest that design decisions enacted in the Sickle Cell Unite group in terms of privacy and use of intense stimulation of emotions may encourage more interactions while higher intensity of executive management in the Sickle Cell Warriors group might inhibit certain kinds of interaction and reduce the overall amount of interactions. At the same time, those rules and strict control of content posted on the page, could lead into more contextual content that leads into longer terms discussion as opposed to strong prompt responses, suggested by the difference in the length of discussion (time to last comment).

Table 4 - Modeling interaction around messages in Unite vs. Warriors group

\begin{tabular}{|l|l|l|l|l|l|l|l|l|l|l|l|l|}
\hline & \multicolumn{4}{|l|}{ Likes } & \multicolumn{3}{l|}{ Comments } & \multicolumn{3}{l|}{ Time to first comment } & \multicolumn{3}{l|}{ Time to last comment } \\
\hline & Coef & $\mathbf{Z}$ & Sig. & Coef & $\mathbf{Z}$ & Sig. & Coef. & $\mathbf{Z}$ & Sig. & Coef. & $\mathbf{Z}$ & Sig. \\
\hline $\begin{array}{l}\text { Unite vs. } \\
\text { Warriors }\end{array}$ & 3.73 & 6.40 & $<.001$ & 3.18 & 5.50 & $<.001$ & -2.92 & -12.14 & $<.001$ & -2.34 & -19.99 & $<.001$ \\
\hline $\begin{array}{l}\text { Leader vs. } \\
\text { Members }\end{array}$ & 5.80 & 5.54 & $<.001$ & 2.23 & 3.41 & .001 & -1.66 & -3.92 & $<.001$ & -.57 & -3.54 & $<.001$ \\
\hline
\end{tabular}

\subsection{Topics of discussions}

To further our understanding of the groups and gain a better insight into the impact of leadership strategies on group dynamics, we randomly selected a set of 128 messages from this two groups (68 from Unite and 60 from Warrior) and manually annotated the topics being discussed in each group. We were interested to assess whether the leadership strategies influence the topics of discussions in addition to the amount of the interaction happening in each group. The top eight categories accounting for $80 \%$ of codes, in order of popularity, include: self-expression (20\%), seeking support (16\%), seeking shared experiences ( $9 \%$ ), sharing information $(8 \%)$, seeking information and encouragement (each $7 \%$ ), advertisement (6\%) and God/Prayer (each 6\%). As shown in Table 5, comparison of messages shows that while some type of messages such as "seeking 
shared experiences" and "sharing information" appears equally between both groups, other kinds of messages are represented significantly differently between the two groups. For example, there are $37 \%$ more advertisement messages on the Unite group while there are $41 \%$ more "self-expression" messages and $43 \%$ more religious (God/prayer) messages on the Warriors group.

Table 5 - Topic of discussion across two groups

\begin{tabular}{|l|l|l|l|l|l|}
\hline & $\begin{array}{l}\text { \# of } \\
\text { post }\end{array}$ & $\%$ & Warrior & Unite & $\begin{array}{l}\% \\
\text { diff }\end{array}$ \\
\hline Self-expression & 80 & 19.75 & 26 & 11 & 41 \\
\hline Seeking support & 66 & 16.3 & 16 & 9 & 28 \\
\hline $\begin{array}{l}\text { Seeking shared } \\
\text { experience }\end{array}$ & 35 & 8.64 & 12 & 14 & 4 \\
\hline $\begin{array}{l}\text { Sharing } \\
\text { information }\end{array}$ & 33 & 8.15 & 8 & 10 & 11 \\
\hline Encouragement & 29 & 7.16 & 4 & 6 & 20 \\
\hline $\begin{array}{l}\text { Seeking } \\
\text { information }\end{array}$ & 29 & 7.16 & 4 & 6 & 20 \\
\hline Advertisement & 25 & 6.17 & 6 & 13 & 37 \\
\hline God/prayer & 24 & 5.93 & 15 & 6 & 43 \\
\hline
\end{tabular}

However, the results are somewhat surprising; for example, given strong use of self by the Unite group leader and the private nature of the group, we expected higher level of "self-expression" in the Unite group as opposed to Warriors group but the results suggest the opposite. While our results suggest differences in content of the discussion in each of these groups, further investigation is needed to better study how the content of the messages reflect leadership strategies.

\section{Discussion and Future Work}

Lieberman and Golant [3] outlined four major leadership strategies used in offline health support groups and suggested that the varying level and intensity of these practices across different groups is associated with varied group outcomes. Prior research has focused on measuring the level of such leadership behavior through conducting subjective survey among the members [3]. In this work, we have attempted to study Lieberman and Golant leadership framework in the context of online health support groups through behavioral measures of the group as well as the leaders' perspective. We particularly focused on two Facebook groups dedicated to patients with Sickle Cell disease. We employed a mixed methods approach to understand the impact of two different health support group structures and leadership approaches on group dynamics.
Our interview results highlights that Lieberman and Golant's framework of leadership in offline health support groups can be observed in the online groups as well. We observed indication of all four leadership strategies: stimulating emotions, providing support and care, meaning attribution, and executive functions in both groups. In accordance with prior research, we observed stimulating emotions as a fundamental function of leadership behaviors. However, the strategies varied across the two groups. While both groups' leaders expressed strong indication of providing support, care, and cognitive structure for the groups, they employed distinct strategies in stimulating emotions and executive management of the groups. They varied the intensity in using personal experiences as stimulating emotion strategies and the intensity in enforcing rules of acceptable behavior in the group.

We further analyzed how these leadership strategies related to the group dynamics. We noted that less intense executive management and higher level of emotion stimulation strategies, while preserving privacy, in the Unite group has led to attracting larger amount of activity and higher amount of interactions; however, a somewhat surprising result is the difference in occurrence of "self-expression" messages. Given a more intense strategy of the Unite group in stimulating emotions, we expected to observe higher number of cases of "self-expression" happening in that group; however, the results suggest the opposite that there were more self-expression messages on the Warriors group. A more in-depth analysis is required to further understand the nature of higher level of interactions in the Unite group and potentially how it influences the continued participation of the members and any indication of their health outcomes.

We acknowledge that the exploratory and nonexperimental nature of our research introduces limitations in terms of close connection between leadership strategies and group outcomes. We hope that our work aspires further research to gain more indepth understanding into the relationship between leadership strategies and group dynamics in online support groups, particularly in terms of the ability to attract a specific group of members, encouraging a particular behavior, and sustaining supportive interactions. Furthermore, we hope our work will bring attention to provide supports for patients with less supported diseases such as Sickle Cell patients, as it was specifically brought up by one of our interviewees who had observed there are stronger support groups for some other diseases such as cancer. In that direction, comparison and contrast of our findings across social media environments and platforms as well as various 
chronic diseases are necessary to be able to study how our findings generalize into other social media environments and other health conditions.

Online health support groups have attracted a good deal of attention from various research communities, including Information Systems' researchers. We hope our work has highlighted a new area within the research community by emphasizing the role of leaders of such groups. We aim to have started a research direction to build a stronger bridge between researchers and practitioners of such groups, to engage the practitioners more closely in our research, and to provide guidelines and technological supports for the leaders of such groups to manage their groups more effectively. As the future direction of our work, we plan to work closely with Sickle Cell online groups in design and development of a dedicated site to patients of Sickle Cell diseases. In particular, we hope to conduct users studies and experiments among individuals on these health support groups to understand their satisfaction with group in connection with different categories of topics. The collaboration will allow us to try to address the technological and information needs of those groups as well as provide us with the possibilities of conducting controlled experiments among the groups to better understand the group processes and the impact of the technology.

\section{Acknowledgement}

We would like to thank the leaders of Sickle Cell Unite and Warriors group for their time to talk to us and provide us with access to the content of their groups. We would also like to thank our annotators, Dr. Yu-Ru Lin for providing the Python code to interface with LIWC dictionary, and $\mathrm{Di} \mathrm{Lu}$ for extracting Facebook messages through the API (names removed for anonymous review).

\section{References}

[1] N. S. Coulson. 2014. Sharing, supporting and sobriety: a qualitative analysis of messages posted to alcohol-related online discussion forums in the United Kingdom. Journal of Substance Use 19, 1-2 (2014), 176-180

[2] Yi-Chia Wang, Robert Kraut, and John M Levine. 2012.To stay or leave?: the relationship of emotional and informational support to commitment in online health support groups. In Proceedings of the ACM 2012conference on Computer Supported Cooperative Work.ACM, 833-842.
[3] M. A. Lieberman and M. Golant. 2002. Leader behaviors as perceived by cancer patients in professionally directed support groups and outcomes. Group Dynamics: Theory, Research, and Practice 6, 4 (2002), 267.

[4] D. M. Kivlighan Jr and J. M. Tarrant. 2001. Does group climate mediate the group leadership-group member outcome relationship?: A test of Yalom's hypotheses about leadership priorities. Group Dynamics: Theory, Research, and Practice5, 3 (2001), 220.

[5] U. Matzat and G. Rooks. 2014. Styles of moderation in online health and support communities: An experimental comparison of their acceptance and effectiveness. Computers in Human Behavior36 (2014),65-75.

[6] S. J Beck and J. Keyton. 2014. Facilitating social support: Member-leader communication in a breast cancer support group. Cancer nursing 37, 1(2014), E36-E43.

[7] J. E. Owen, E. O'Carroll Bantum, and M. Golant. 2009. Benefits and challenges experienced by professional facilitators of online support groups for cancer survivors. Psycho-Oncology 18, 2 (2009), 144-155.

[8] Foster, G., Taylor, S. J., Eldridge, S. E., Ramsay, J., \& Griffiths, C. J. (2007). Self-management education programmes by lay leaders for people with chronic conditions. Cochrane Database Syst Rev, 4(4).

[9] Sickle Cell Warrior group:

https://www.facebook.com/SickleCellWarriors

[10] Sickle Cell Unite group:

https://www.facebook.com/groups/527861263907134/

[11] Facebook Tips: What's the Difference between a Facebook Page and Group?

https://www.facebook.com/notes/facebook/facebook-tipswhats-the-difference-between-a-facebook-page-andgroup/324706977130/

[12] H. Boeije. 2002. A purposeful approach to the constant comparative method in the analysis of qualitative interviews. Quality and quantity 36, 4 (2002),391-409.

[13] J. Arguello, B. S. Butler, E. Joyce, R. Kraut, K. S Ling, C. Rose, and X. Wang. 2006. Talk to me: foundations for successful individual-group interactions in online communities. In Proceedings of the SIGCHI conference on Human Factors in computing systems. ACM, 959-968. 